\title{
Pengukuran Kinerja Layanan Akademik Dengan Maturity Level Dan Analisis It Balanced Scorecard Berdasarkan Perspektif Orientasi Pengguna
}

\author{
Didin Herlinudinkhaji ${ }^{1}$
}

\begin{abstract}
The academic activities in university are very important during pandemic, where of the activities are carried out online. Universities need to have a strategy to be able to carry out academic service so that they very well, one of which is carry out measurements using maturity levels and IT Balanced Scorecard. This research, an analysis of the IT Balanced Scorecard from a user orientation perspective was carried out to the performance of some indicators so that they could find out the final score of these indicators. The final score shows the performance value of each indicator so that it can carry out an assessment using maturity level that can be used by the leaders to establish the next strategic. The results of this study show that the analysis of the IT Balanced Scorecard and maturity level can know the effect of each performance indicator.
\end{abstract}

Intisari- Kegiatan akademik di Perguruan Tinggi sangatlah penting terutama di masa pandemi yang sebagian besar kegiatannya dilakukan secara daring. Perguruan tinggi perlu memiliki strategi untuk dapat melaksanakan pelayanan akademik supaya berjalan dengan baik salah satunya dengan melaksanakan pengukuran dengan menggunakan maturity level dan analisis IT balanced scorecard. Pada penelitian ini dilakukan analisis IT Balanced Scorecard perspektif orientasi pengguna untuk mengetahui kinerja dari beberapa indikator sehingga dapat mengetahui skor akhir indikator tersebut. Penskoran akhir menunjukkan nilai kinerja dari masing-masing indikator sehingga dapat melakukan penilaian dengan maturity level yang dapat digunakan pimpinan perusahaan/organisasi untuk menentukan langkah stragis berikutnya. Hasil penelitian tersebut menunjukkan bahwa analisis IT Balanced Scorecard dan maturity level dapat mengetahui pengaruh dari masing-masing indikator kinerja.

Kata Kunci-IT Balanced Scorecard, Kinerja Layanan Akademik, Maturity Level, IT BSC, Layanan Akademik.

\section{PENDAHULUAN}

Teknologi informasi sudah menjadi kebutuhan untuk sebuah institusi terutama Perguruan Tinggi. Sebagian besar kegitan akademik pada perguruan tinggi menggunakan teknologi informasi sebagai alat utamanya.

Di masa pandemi, kegiatan akademik terutama proses pembelajaran dilakukan secara daring, kegiatan seperti pelayanan akademik sebagian besar dilaksanakan secara daring. Untuk mendukung pelayanan akademik yang prima maka diperlukan sebuah strategi dalam proses pelayanan akademik tersebut.

${ }^{I}$ Fakultas Sains dan Teknologi Jurusan Bisnis Digital, Universitas Ivet Semarang, Jl. Sunan Kudus Sembung Cepiring, RT.08/02 Kec. Cepiring Kab. Kendal Jawa Tengah tlp: 085227356575; e-mail:didnt.aji@gmail.com
Mahasiswa mempunyai ekspektasi yang besar terhadap universitas untuk memberikan pelayanan yang baik. Pelayanan yang baik sangat diperlukan agar mahasiswa tidak merasa kesulitan ketika mengikuti kegiatan akademik, seperti perkuliahan, praktikum, tugas akhir, bimbingan tugas akhir, dan pelayanan administrasi. Sehingga proses kegiatan akademik tersebut perlu dikelola dengan baik.

Information Technology Balanced Scorecard (IT Balanced Scorecard) merupakan salah satu analisis yang dapat dapat digunakan untuk mengukur terhadap kinerja Sistem Informasi Akademik [4]. Sebelum membuat sistem informasi akademik perlu melakukan rancangan terhadap tata kelola sistem informasi. IT Balanced Scorecard dapat digunakan untuk merancang tata kelola sistem informasi [7]. Hasil tersebut menunjukkan bahwa terdapat peningkatan kinerja berdasarkan indikator efektifitas pelayanan administrasi akademik, kepuasan operator sistem, peningkatan kompetensi operator sistem, kualitas sistem dan peningkatan keahlian staf IT [4].

Pelayanan akademik di perguruan tinggi yang diterima mahasiswa minimal terdiri dari 3 jenis pelayanan yang meliputi pelayanan akademik atau kurikuler, pelayanan administrasi, dan pelayanan ekstra kurikuler. Pelayanan akademik meliputi : peraturan akademik, kurikulum, perkuliahan, praktikum, bimbingan akademik, tugas akhir, evaluasi, peralatan perkuliahan, laboratorium, dan lain-lain yang berkaitan dengan akademik. Unsur-unsur yang mendukung dalam kegiatan akademik meliputi unsur tenaga akademik seperti dosen, unsur penunjang akademik yaitu laboran, dan tenaga administrasi akademik. Selain unsur tersebut, terdapat juga unsur penunjang akademik yang lain seperti sarana dan prasarana yang menunjang untuk menentukan kualitas layanan akademik yang diberikan.

Untuk menjaga kualitas terhadap pelayanan akademik tersebut, maka perlu dilakukan pengukuran terhadap kinerja layanan akademik. Bagaimana bagian akademik telah melakukan pelayanan dengan optimal dan apakah pelayanan yang sudah diberikan tersebut telah mampu memberikan kepuasan yang sesuai dengan kebutuhan mahasiswa atau belum? Maka ini perlu dilakukan pengukuran terhadap kinerja layanan akademik dengan melakukan penelitian. Penelitian ini dilakukan dengan menggunakan maturity level dan analisis IT Balanced Scorecard berdasarkan perspektif orientasi pengguna. 


\section{KAJIAN LITERATUR}

\section{A. Penelitian Terdahulu}

Penelitian pertama yang sudah pernah dilakukan sebelumnya berjudul "Evaluasi Kinerja Sistem Informasi Akademik Menggunakan IT Balanced Scorecard Pada Universitas Serambi Mekkah Banda Aceh". Penelitian ini dilakukan untuk melakukan evaluasi terhadap kinerja sistem informasi akademik termasuk di dalamnya sumber daya yang mendukung terhadap sistem akademik tersebut. Hasil dari penelitian ini menunjukkan laporan kinerja pada bagian administrasi akademik, operator sistem, kualitas sistem, dan staff IT [5].

Penelitian kedua yang sudah pernah dilakukan sebelumnya berjudul "Peningkatan Kinerja Sistem E-learning dalam Perspektif Universitas 4.0 Menggunakan Kerangka IT Balances Scorecard". Penelitian ini dilakukan untuk melakukan evaluasi kinerja e-learning agar selaras dengan tujuan bisnis. Penelitian ini memfokuskan pada kerangka IT Balanced Scorecard berdasarkan 4 perspektif. Hasil dari penelitian ini berupa nilai dari masing-masing 4 perspektif [9].

Penelitian ketiga yang sudah pernah dilakukan sebelumnya berjudul "Analisis Pengukuran Kinerja Divisi IT Menggunakan IT Balanced Scorecard pada PT. XYZ". Penelitian ini dilakukan untuk mengukur kinerja IT yang diterapkan perusahaan sehingga dapat mempengaruhi perkembangan perusahaan. Penelitian ini menggunakan IT Balanced Scorecard berdasarkan 4 perspektif. Hasil dari penelitian ini menghasilkan kinerja pada divisi IT yang dapat mempengaruhi perkembangan perusahaan sehingga perusahaan dapat menyusun strategi perusahaan [8].

Penelitian keempat yang sudah pernah dilakukan sebelumnya berjudul "Measurement of The Effectiveness Strategy IS/IT to Business Strategy with IT Balanced Scorecard Methode at Binus International JOSEPH WIBOWO CENTER". Penelitian ini dilakukan untuk mengetahui apakah strategi SI/TI sejalan dengan strategi bisnis JWC. Pengukuran efektivitas strategi SI/TI terhadap strategi bisnis ini menggunakan metode IT Balance Scorecard, SWOT untuk mendukung penentuan strategi, serta metode Analytical Hierarchy Process dalam penentuan bobot kepentingan. Hasil dari penelitian ini berupa rekomendasi strategi SI/TI terbaik untuk mendukung secara penuh strategi bisnis yang dilakukan oleh JWC [4].

Penelitian kelima yang sudah pernah dilakukan sebelumnya berjudul "Perencanaan Strategis Sistem Informasi Pengukuran Kinerja Dosen dengan menggunakan IT Balanced Scorecard. Penelitian ini dilakukan untuk melakukan perencanaan strategis sistem informasi pengukuran kinerja dosen. Penelitian ini dilakukan dengan pendekatan IT Balanced Scorecard. Hasil dari penelitian ini berupa beberapa indikator yang dijadikan alat untuk mengukur kinerja dosen [10].

Penelitian yang penulis lakukan mengacu pada penelitian terdahulu yang sama-sama menganalisis tentang kinerja, baik itu kinerja dari sistem ataupun kinerja sumber daya manusia menggunakan analisis IT Balacnced Scorecard dengan 4 perspektif. Penelitian yang penulis lakukan mengarah pada layanan akademik menggunakan Maturity Level dan IT Balanced Scorecard berdasarkan perspekrif pengguna.

\section{B. Critical Success Factor}

Critical Success Factor (CSF) atau faktor penentu keberhasilan adalah salah satu faktor dalam kegiatan perusahaan yang berpengaruh kuat pada kemampuan perusahaan untuk mencapai tujuannya. Sehingga CSF dijadikan indikator untuk menilai kinerja [14]. Kinerja merupakan hasil kerja dari pegawai/karyawan yang dihasilkan uncuk mencapai tujuan organisasi/perusahaan sehingga memunculkan kepuasan atau ketidakpuasan terhadap kinerja tersebut. Kinerja yang maksimal didapatkan dari kualitas dan kuantitas yang dicapai oleh pegawai/karyawan dalam melaksanakan tugas yang dibebankan.

\section{Maturity Level}

Maturity level digunakan untuk mengukur level perkembangan manajemen proses berdasarkan penilaian atau scoring [12] sehingga pihak manajemen dapat mengetahui level atau tingkatan pada bagian yang akan dilakukan penilaian. Maturity model terdiri dari $0-5$ level. Tabel 1 menunjukkan maturity level [1][15].

TABEL 1

MATURITY MODEL

\begin{tabular}{ll}
\hline \multicolumn{1}{c}{ Level } & \multicolumn{1}{c}{ Kriteria kematangan } \\
\hline $\begin{array}{l}\text { Level 0 Non } \\
\text { Existent }\end{array}$ & Management Processes are not applied at all \\
\hline Level 1 Initial & Processes are ad hoc and disorganized \\
\hline Level 2 Repeatable & Processes follow a regular pattern \\
\hline Level 3 Defined & Processes are documented and communicated \\
\hline $\begin{array}{l}\text { Level 4 Managed } \\
\text { and Measurable }\end{array}$ & Processes are monitored and measured \\
\hline Level 5 Optimized & Good practices are followed and automated \\
\hline
\end{tabular}

\section{Information Technology Balanced Sorecard (IT Balanced} Scorecard)

IT Balanced Scorecard merupakan framework yang dikembangkan oleh Van Grembergen dan Van Bruggen pada tahun 1997 yang digunakan untuk mengukur kinerja teknologi informasi pada bagian teknologi informasi. IT Balanced Scorecard terdiri dari beberapa perspektif yang dapat dijadikan standar untuk mengukur kinerja sumber daya manusia [13] maupun kinerja teknologi informasi [14]. Perspektif pada IT Balanced Scorecard terdiri dari 4 yaitu Perspektif Orientasi Pengguna, Perspektif Kontribusi Perusahaan, Perspektif Operasional, dan Perspektif Orientasi Masa Depan.

IT Balanced Scorecard bertujuan agar pengguna dapat menyesuaikan perencanaan dan aktivitas pada sistem informasi sebagai kebutuhan organisasi, menyediakan pengukuran untuk mengevaluasi efektivitas sistem informasi, meningkatkan kinerja sistem informasi, dan pencapaian hasil yang seimbang di antara Stakeholder [11]. Tabel 1 Menunjukkan perspektif pada IT Balanced Scorecard [5][11]. Dalam penelitian ini penulis hanya fokus pada perspektif orientasi pengguna. Perspektif orientasi pengguna (user orientation) adalah perspektif yang mengevaluasi kinerja IT berdasarkan cara 
pandang pengguna bisnis (pelanggan kita). Dalam perspektif orientasi pengguna organisasi melakukan assesment untuk mengetahui kepuasan pengguna dan loyalitas [14].

TABEL 2

PERSPEKTIF IT BALANCED SCORECARD

\begin{tabular}{|c|c|}
\hline User Orientation & Business Contribution \\
\hline $\begin{array}{l}\text { How do users view the IT } \\
\text { Department? }\end{array}$ & $\begin{array}{l}\text { How does management vies the IT } \\
\text { department? }\end{array}$ \\
\hline Mission & Mission \\
\hline $\begin{array}{l}\text { to be the preferred supplier or } \\
\text { information system } \\
\text { obiectives }\end{array}$ & $\begin{array}{l}\text { To obtain a reasonable Business } \\
\text { contribution from IT } \\
\text { Objectives }\end{array}$ \\
\hline 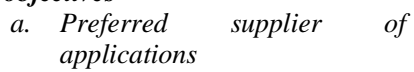 & $\begin{array}{l}\text { a. } \\
b . \quad \text { Bustrol of IT expenses } \\
\text { Bulues of IT project }\end{array}$ \\
\hline $\begin{array}{ll}\text { b. } & \begin{array}{l}\text { Preferred supplier of vs } \\
\text { proposer of best solutioh }\end{array} \\
c . & \text { Partnership with users } \\
\text { d. } & \text { User satisfaction }\end{array}$ & $\begin{array}{l}\text { c. Provision of new business } \\
\text { capabilities }\end{array}$ \\
\hline Opertion Excellence & tation \\
\hline $\begin{array}{l}\text { a. Efficient and effective } \\
\text { developments }\end{array}$ & $\begin{array}{l}\text { a. Training and education of IT } \\
\text { staff }\end{array}$ \\
\hline b. $\begin{array}{l}\text { Efficient and } \\
\text { operations }\end{array}$ & $\begin{array}{ll}b . & \text { Expertise of IT staff } \\
c . & \text { Research into emerging } \\
& \text { technologies } \\
d . & \text { Age of application portofolio }\end{array}$ \\
\hline
\end{tabular}

\section{METODE PENELITIAN}

Penelitian yang penulis lakukan berbentuk studi kasus dengan menggunakan metode survey kuesioner (Jogiyanto, 2011). Penelitian ini termasuk penelitian kualitatif. Penelitian ini menghasilkan temuan-temuan serta rekomendasi yang dapat dijadikan dasar untuk pengambilan keputusan oleh manajemen.

\section{A. Metode Pengumpulan Data}

Pada penelitian ini, metode pengumpulan data yang penulis lakukan yaitu dengan studi literatur dan survey kuesioner. Studi literatur digunakan untuk mengkaji literatur yang berkaitan dengan layanan akademik. Penulis juga melakukan kajian terhadap penelitian tentang kinerja dengan analilsis IT Balanced Scorecard dan penelitian yang berkaitan dengan Maturity Level.

Survey kuesioner dilakukan untuk mendapatkan data langsung dari objek penelitian. Kuesioner tersebut didapatkan dari mahasiswa yang merupakan pengguna layanan akademik.

\section{B. Alur Penelitian}

Pada penelitian ini, alur penelitian terdapat beberapa langkah yang dilakukan seperti terlihat pada Gbr. 1 alur penelitian. Alur penelitan tersebut dapat dijelaskan sebagai berikut :

1) Studi Literatur

Pada tahapan ini, penulis mengkaji sumber literatur yang relevan berupa jurnal maupun konferensi untuk mendapatkan informasi tentang penelitian terdahulu yang relevan dengan penelitian ini.

2) Pengumpulan Data

Pada tahapan ini, penulis mendapatkan data dan informasi dengan menggunakan studi pustaka dan survey kuesioner. Studi pustaka sebelumnya sudah didapatkan pada langkah awal. Survey kuesioner didapatkan dari pengguna layanan akademik dalam hal ini mahasiswa.

3) Analisis dengan Maturity Level dan IT Balanced Scorecard

Pada tahapan ini, langkah pertama yang dilakukan dengan merumuskan faktor penentu keberhasilan atau indikator dengan perspektif orientasi pengguna, hasil dari analisis ini selanjutnya dilakukan penghitungan skor akhir untuk masing-masing indikator. Langkah berikutnya melakukan penghitungan maturity level terhadap layanan akademik yang indikatornya didapatkan dari analisis IT Balanced Scorecard perspektif orientasi pengguna sehingga akan didapatkan skor pada masing-masing layanan akademik.

4) Hasil Analisis

Hasil analisis ini berupa penskoran kinerja dan rekomendasi perbaikan layanan akademik.

5) Penarikan Kesimpulan dan Saran

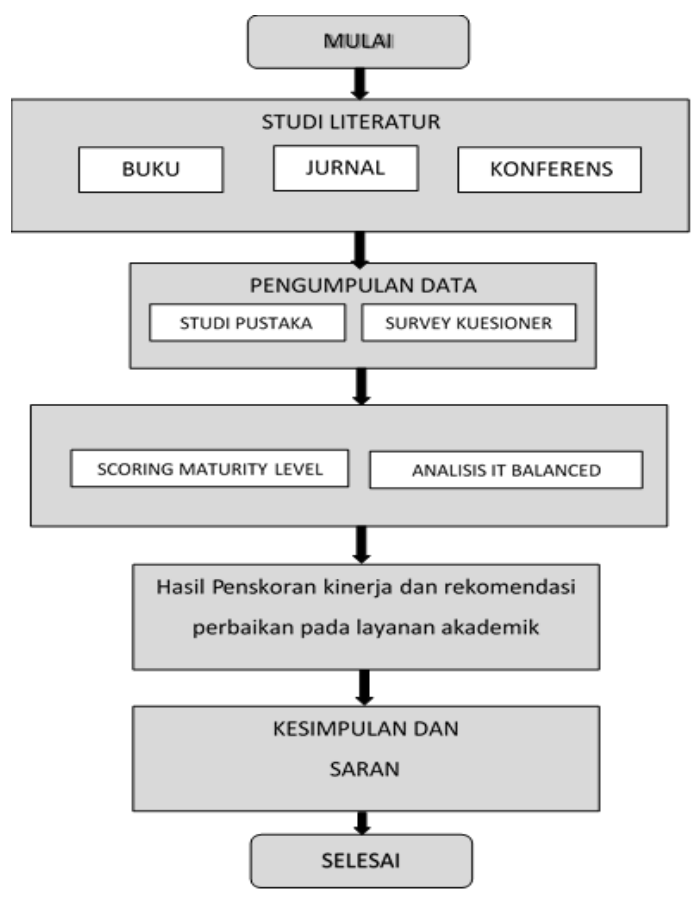

Gbr. 1 Alur Penelitian 


\section{HASIL DAN PEMBAHASAN}

\section{A. Indikator Penilaian}

Indikator penilaian terhadap layanan akademik didasarkan atas faktor penentu keberhasilan atau CSF layanan akademik. Rumusan CSF berdasarkan IT Balanced Scorecard perspektif orientasi pengguna. Indikator yang didapatkan dari layanan akademik berupa perkuliahan, dosen, bimbingan tugas akhir, dan sarana prasarana penunjang. Rumusan CSF ditunjukkan pada tabel 3 indikator penilaian di bawah ini :

TABEL 3

INDIKATOR PENILAIAN

\begin{tabular}{cll}
\hline No & CSF & Indikator \\
\hline 1 & Perkuliahan/pembelajaran & Kurikulum \\
& & Proses pembelajaran \\
& & Materi kuliah \\
& & Penugasan \\
& & Penilaian \\
\hline 2 & Dosen & Kompetensi pedagogik \\
& & Kompetensi profesional \\
& & Kompetensi personal \\
& & Kompetensi sosial \\
\hline 3 & Bimbingan akademik & Sikap tanggap \\
& & Responsif \\
& & Sikap dalam pelayanan \\
\hline 4 & Sarana prasarana penunjang & Ruang kuliah \\
& & Laboratorium \\
& & Perpustakaan \\
& & Internet/wifi \\
\hline
\end{tabular}

\section{B. Analisis IT Balanced Scorecard}

IT Balanced Scorecard terdiri dari 4 perspektif diantaranya corporate contribution, user orientation, operationel excellence, dan future orientation. Dari keempat perspektif tersebut, penulis melakukan analisis berdasarkan user orientation. Perspektif tersebut melihat cara pandang bisnis berdasarkan orientasi pengguna, kepuasan pengguna, dan loyalitas pengguna. Indikator yang sudah didapatkan kemudian dilakukan penghitungan penskoran yang ditunjukkan pada tabel 4 di bawah ini :

TABEL 4

SKOR AKHIR

\begin{tabular}{llllll}
\hline $\begin{array}{l}\text { Faktor } \\
\text { Penentu }\end{array}$ & Bobot & Target & Realisasi & Score & $\begin{array}{l}\text { Score } \\
\text { Akhir }\end{array}$ \\
\hline Perkuliahan & 32 & 213 & 164 & 350,333 & $22,753 \%$ \\
\hline Dosen & 27 & 296 & 179 & 241,893 & $16,784 \%$ \\
\hline $\begin{array}{l}\text { Bimbingan } \\
\text { Akademik }\end{array}$ & 10 & 90 & 48 & 106,666 & $5,333 \%$ \\
\hline $\begin{array}{l}\text { Sarana } \\
\text { Prasarana }\end{array}$ & 31 & 56 & 44 & 213,024 & $16,756 \%$ \\
\hline TOTAL & $\mathbf{1 0 0}$ & & & & $\mathbf{6 1 , 6 3 \%}$ \\
\hline
\end{tabular}

Tabel 4 di atas menunjukkan skor akhir untuk masingmasing faktor penentu keberhasil IT Balanced Scorecard perspektif orientasi pengguna. Masing faktor penentu keberhasilan terdiri dari beberapa indkator yang memiliki nilai akhir berbeda-beda yang ditunjukkan pada tabel 5 .

Tabel 5 menunjukkan nilai dari masing-masing indikator faktor penentu keberhasilan. Indikator tersebut menunjukkan keterwakilan dari masing-masing faktor penentu keberhasilan berdasarkan orientasi pengguna.
TABEL 5

SKOR AKHIR INDIKATOR

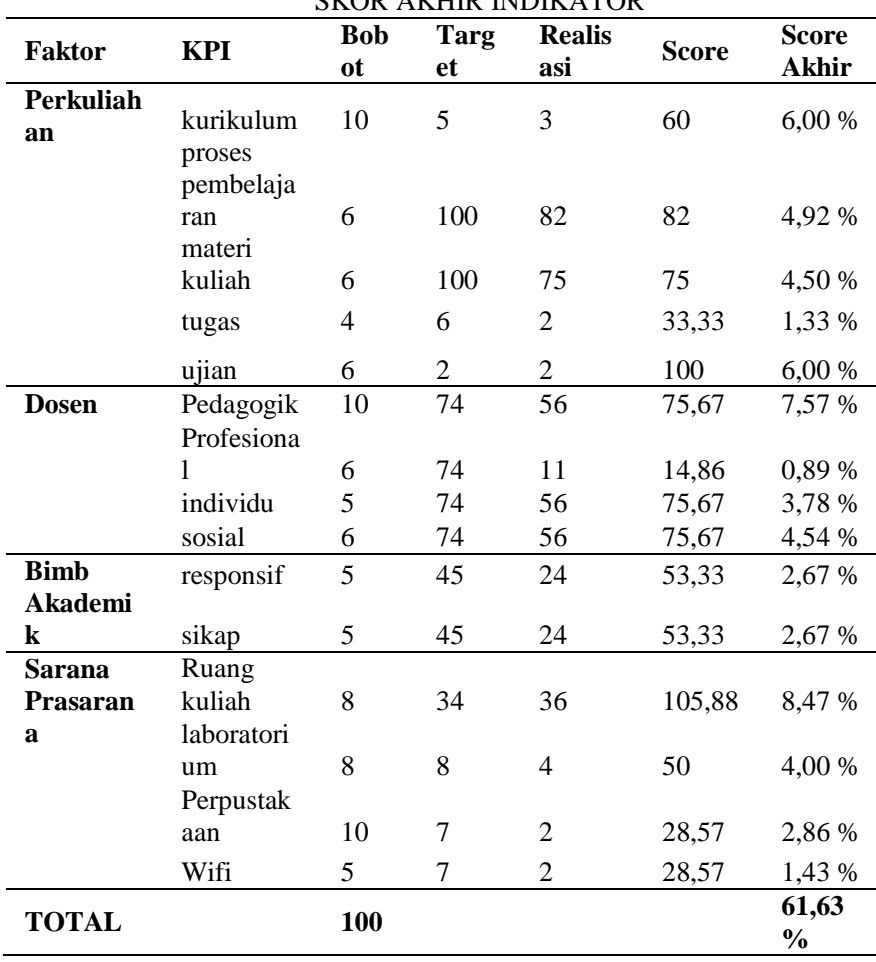

\section{Penghitungan Maturity Level}

Analisis ini berdasarkan penghitungan maturity level $0-5$. Hasil ini didapatkan dari pernyataan yang didapatkan dari survey kuesioner terhadap bagian layanan akademik yang terdiri dari perkuliahan, dosen, bimbingan akademik, serta sarana prasarana penunjang. Untuk mendapatkan tingkat kematangan, penulis menggunakan teknik standar penilaian maturity level. Teknik ini dilakukan dengan memberikan nilai terhadap kuesioner tersebut ke dalam standar penilaian maturity level, seperti ditunjukkan pada Tabel 6 di bawah ini.

TABEL 6

STANDAR PENILAIAN MATURITY LEVEL

\begin{tabular}{ll}
\hline Pernyataan & Nilai \\
\hline Tidak Setuju & 0 \\
\hline Kurang Setuju & 0,33 \\
\hline Setuju & 0,66 \\
\hline Sangat Setuju & 1 \\
\hline
\end{tabular}

Menentukan indikator dari objek yang diteliti. Nilai Maturity Level dari masing-masing indikator tersebut ditunjukkan pada tabel 7 di bawah ini :

TABEL 7

NILAI MATURITY LEVEL INDIKATOR

\begin{tabular}{lcl}
\hline Indikator & Index & $\begin{array}{l}\text { Maturity } \\
\text { Level }\end{array}$ \\
\hline Perkuliahan & 3,03 & 3 \\
\hline Dosen & 3,38 & 3 \\
\hline Bimbingan Akademik & 2,79 & 3 \\
\hline Sarana Prasarana & 2,96 & 3 \\
\hline
\end{tabular}




\section{Hasil Akhir}

Hasil pengukuran IT Balance Scorecard dari keseluruhan prespektif akan di nilai menggunakan Evaluasi Pengukuran dengan 5 kategori bobot / range presentase sebagai berikut berdasarkan range penilaian kinerja TI dalam hal ini sesuai dengan data yang dapat dilihat pada Score Akhir dalam perspektif IT Balanced Scorecard.

Dengan hasil penilaian tersebut dapat dilihat dan juga memberikan gambaran tentang kinerja TI sehingga dapat dijadikan pedoman oleh pimpinan untuk mengambil langkahlangkah yang tepat dalam menyelesaikan masalah tersebut.

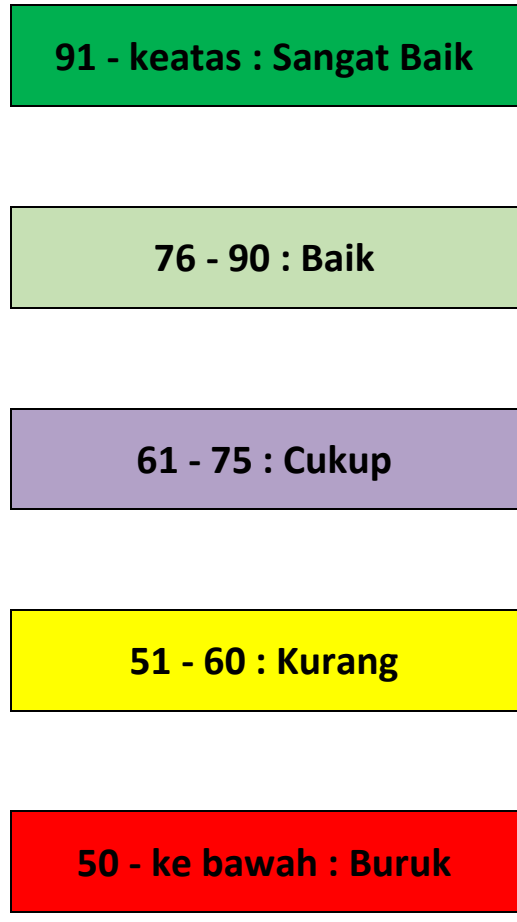

Gbr 2. Range prosentase

\section{KESIMPULAN}

Berdasarkan data hasil penelitian dapat disimpulkan bahwa, analisis IT Balanced Scorecard dapat digunakan untuk menentukan kinerja berdasarkan analisis nilai akhir dari ketercapaian layanan akademik. Dari hasil analisis tersebut dapat digunakan untuk melakukan pengukuran tingkat kematangan berdasarkan perspektif orientasi pengguna sehingga pimpinan mengetahui posisi kematangan perusahaan/organisasi tersebut.

Skor pencapaian masing-masing indikator kinerja juga menunjukkan bahwa masing-masing bagian memiliki keterkaitan untuk mendukung layanan akademik yang lebih baik. Hasil penelitian ini dapat dijadikan dasar bagi manajemen untuk melakukan langkah-langkah yang tepat dapat memperbaiki layanan akademik.

\section{UCAPAN TERIMA KASIH}

Ucapan terima kasih penulis sampaikan kepada istri tercinta yang selalu mendukung beserta anak-anak yang selalu mendampingi. Ucapan terima kasih juga penulis sampaikan kepada UNISS Kendal yang telah memberikan tempat untuk melakukan penelitian. Terima kasih disampaikan juga kepada pengelola Jurnal JSI yang telah bersedia memberikan tempat untuk publikasi jurnal penelitian.

\section{REFERENSI}

[1] Dewi S.R., Maturity Level Assesment for ERP System Investment Using Val IT Framework, Procedia Computer Science 161, 250-257, 2019

[2] Dewi F. and Mahendrawathi ER, Business Process Maturity Level of MSMEs in East Java Indonesia, Procedia Computer Science 161, 1098$1105,2019$.

[3] Haryanti, Tining and Pribadi A., E-commerce Service Design Readines using ITIL Framework with IT Balanced Scorecard Objective (Case Study : University E-commerce), Procedia Computer Science 161, 283 290, 2019.

[4] Hendy Wijaya dan Erny Caroline, Measurement of The Effectivess Strategy Is/It To Business Strategy With It Balanced Scorecard Method At Binus International Joseph Wibowo Center, Journal of Technology Information, 2020, vol. 6 No. 1.

[5] Muhammad, Rizal Munadi, M. Subianto, Evaluasi Kinerja Sistem Informasi Akademik Menggunakan IT Balanced Scorecard Pada Universitas Serambi Mekkah Banda Aceh, Jurnal Infromatika UPGRIS, 2018, Vo. 4, No. 1.

[6] Solechan A., Prasandy T., Rancang bangun Tata Kelola Kinerja Perguruan Tinggi menggunakan IT Balanced Scorecard, Jurnal Sistem Informasi Bisnis, 2016, 01.

[7] Nibras Faiq M, Kusrini, Asro Nasrini, Menggunakan Cobit 4.1 dan Balaced Scorecard Untuk Merancang Tata Kelola Sistem Informasi, Jurnal Informa, 2021, Vol. 7, No. 1.

[8] Edi Gunawan, Analisis Pengukuran Kinerja Divisi It Menggunakan It Balanced Scorecard Pada Pt. XYZ, Jurnal Manajemen Bisnis dan Kewirausahaan, 2019, Vol. 3, No. 3.

[9] Safitri N.A., Herdiansyah M.I., Peningkatan Kinerja Sistem E-Learning Dalam Perspektif Universitas 4.0 Menggunakan Kerangka It Balanced Scorec, Gema Teknologi, 2020, No. 1.

[10] Syarifudin G, Perencanaan Strategis Sistem Informasi Pengukuran Kinerja Dosen Dengan Menggunakan It-Balance Scorecard, Jurnal Ilmiah SISFOTENIKA, 2013, Vol. 3, No. 1.

[11] Nainggolan D.Y., Wijaya A.F., Analisis Kinerja Sistem Pengolahan Data Berbasis Web Menggunakan It Balanced Scorecard Sebagai Sarana Untuk Menunjang Kinerja Pegawai Pada Badan Pusat Statistik (BPS) Kabupaten Sragen, Jurnal SITECH, 2019, Vol 2, No. 1.

[12] Pawan E, Utama E., Nasiri A, Mengukur Tingkat Kematangan Tata Kelola Sistem Informasi Akademik Menggunakan COBIT 4.1 dan Balanced Scorecard, Citec Journal, 2018, Vol. 5, No. 2.

[13] Niven P.R., Balanced Scorecard Step by Step, Maximing Performance and Maintaining Results, John Wiley \& Sons Inc, 2th edition, 2006.

[14] Keyes J., Implementing the IT Balanced Scorecard Aligning with Corporate Srategy, Auerbach Publication, Taylor \& Francis Group, 2005 .

[15] Sakinah F, Setiawan B., Indeks Penilaian Kematangan (Maturity) Manajemen Keamanan Layanan TI, Jurnal Teknik Pomits, 2013, Vol. 2 , No. 1 .

[16] Jogiyanto, Pedoman Survey Kuesioner : Pengembangan Kuesioner mengatasi bias dan Meningkatkan Respon, BPFE, Jogjakarta, 2011.

[17] Jogiyanto, Metode Penelitian Sistem Informasi, Penerbit ANDI, Jogjakarta, 2008. 


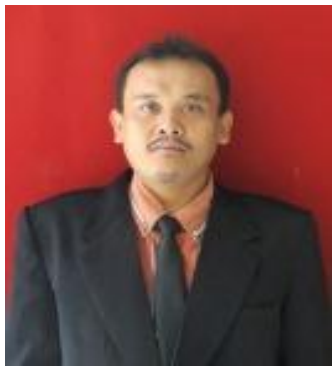

Didin Herlinudinkhaji. Pemalang, 22 Februari 1981. Pendidikan dari SD s.d. SMA diselesaikan di Kabupaten Pemalang. S-1 Jurusan Sistem Informasi Universitas Dian Nuswantoro Semarang Lulus tahun 2006, S2 Sistem Informasi Universitas Diponegoro Lulus tahun 2014. Pernah Bekerja sebagai teknisi komputer kid Semarang dan juga pernah sebagai tenaga pengajar pada SMA di Kabupaten Kendal, minat pada dunia pendidikan terasa sejak tahun 2011 dikala mengelola lab komputer untuk SMA. Bekerja sebagai dosen sejak tahun 2015 s.d. sekarang. Beberapa jurnal yang pernah ditulis diantaranya Audit Tata Kelola TI dengan ITIL V3 tahun 2016, Evaluasi Layanan Sistem Informasi Akademik Berbasis Cobit 4.1, Evaluasi Layanan Teknologi Informasi ITIL v3 Domain Service Design. 